\title{
Lysine-induced premature transcription termination in the lysC operon of Bacillus subtilis
}

\author{
Sunita Kochhar $†$ and Henry Paulus
}

Author for correspondence: Henry Paulus (Boston Biomedical Research Institute). Tel: +1 6177422010 . Fax: +16175236649. e-mail: paulus@bbri.harvard.edu

Boston Biomedical Research Institute, 20 Staniford Street, Boston, MA 02114, USA and Department of Biological Chemistry and Molecular Pharmacology, Harvard Medical School, Boston, MA 02115, USA

\begin{abstract}
The expression of the Bacillus subtilis lysC operon, which encodes the first specific enzyme of lysine biosynthesis, is controlled by the availability of the end product, lysine. The question of whether lysine exerts its control by inducing premature termination of transcription was addressed using Northern blot analysis. Whereas lys-C-specific RNA from lysine-starved B. subtilis consisted primarily of the expected full-length mRNA (1.6 kb), that from bacteria grown with an excess of lysine consisted of a truncated $0.27 \mathbf{~ k b}$ RNA in place of the full-length $1.6 \mathrm{~kb}$ transcript. On the other hand, a B. subtilis aecA mutant, in which the lysC operon was derepressed owing to a single nucleotide substitution in the region corresponding to the lysC leader transcript, produced full-length lysC mRNA, but no 0.27 kb RNA, even during growth with excess lysine. Mapping of the truncated $0.27 \mathrm{~kb}$ lysC RNA by hybridization with oligonucleotide probes showed that it corresponded to the upstream portion of the lysC leader transcript, extending from the transcription initiation site to a putative rho-independent terminator element. Quantitative transcript analysis by hybridization with specific oligonucleotides showed that lysine did not affect the number of IysC-specific RNA molecules but promoted the stoichiometric replacement of full-length mRNA with truncated $0.27 \mathrm{~kb}$ molecules. These results indicate that lysine regulates the expression of the lysC operon by effecting the premature termination of transcription at a rho-independent terminator site in the lysC leader region and that the site of the aecA mutation, far upstream of the putative terminator element, must play an essential role in premature transcription termination by a mechanism which is not yet understood.
\end{abstract}

Keywords: aspartokinase, attenuation, lysine biosynthesis, aec $A$ locus

\section{INTRODUCTION}

The Bacillus subtilis lys $C$ operon, which encodes the inphase overlapping genes for the subunits of the lysinesensitive aspartokinase, has an extensive untranslated leader region which appears to play a crucial role in the negative control of the operon by lysine (Paulus, 1993). When lysine is present in excess, the lys $C$ operon is repressed more than 100 -fold, but mutations at specific sites in the lys $C$ leader can completely overcome this repressive effect (Lu et al., 1991, 1992). Examination of the nucleotide sequence of the lys $C$ leader transcript (Chen $e t$

†Present address: National Botanical Research Institute, Rana Pratap Marg, PB 436, Lucknow-226001, UP, India. al., 1987) reveals the potential for considerable secondary structure; this includes a stem-loop structure followed by a run of uridylates, characteristic of rho-independent transcription terminators (Fig. 1). The putative rhoindependent terminator is preceded by additional stemloops which can assume an alternative conformation in which the terminator is no longer functional, reminiscent of the transcription attenuators found in many biosynthetic operons of Escherichia coli (Kolter \& Yanofsky, 1982). Indeed, like the transcription attenuators controlling amino acid biosynthesis in $E$. coli, the lys $C$ leader contains an open reading frame encoding a lysine-rich oligopeptide that overlaps the first of the stem-loops. However, in spite of the striking similarity to the enterobacterial transcription attenuators, there has been no evidence to support the involvement of premature 
transcription termination in the control of the $B$. subtilis lys $C$ operon. On the contrary, the majority of cis-acting mutations that lead to derepression, including those known as aec $A$ (Magnusson et al., 1983; Mattioli et al., 1979; Vold et al., 1975; Yeh \& Steinberg, 1978), are at a site which has no obvious structural or functional connections with any of the putative transcription attenuator elements (Lu et al., 1991, 1992).

In this paper, we describe the results of transcript analyses which show that lysine promotes the accumulation of prematurely terminated RNA molecules, suggesting that lysine-dependent transcription attenuation plays a major role in the control of the lys $C$ operon of $B$. subtilis.

\section{METHODS}

Materials. Restriction endonucleases, T4 DNA ligase and T4 polynucleotide kinase were purchased from New England Biolabs; T3 RNA polymerase and Bluescript II plasmid $\mathrm{pBC}$ $\mathrm{KS}^{+}$from Stratagene; and $\left[\gamma^{32} \mathrm{P}\right] \mathrm{ATP}$ and $\left[\alpha^{32} \mathrm{P}\right] \mathrm{CTP}$ from Du Pont. Oligonucleotides were synthesized on a Milligan Expedite DNA synthesizer using phosphoramidite chemistry.

Bacterial strains and growth conditions. The following strains of B. subtilis were used in this work: strain $1 \mathrm{~A} 8$ (aroD120 lys 1 $\operatorname{trpC2}$ ) (Dedonder et al., 1977) and B. subtilis strain VB217 (phe $A 1 \operatorname{trpC2} S_{u l^{R}}$ aec A3) (Yeh \& Steinberg, 1978). Strains were grown in the minimal medium of Anagnostopoulous \& Spizizen (1961) as described earlier (Lu et al., 1991). Cells growing in limiting lysine $(0.012 \mathrm{mM})$ were harvested $1 \mathrm{~h}$ after the culture reached a plateau density of 70 Klett units (filter no. 54); cells growing with an excess of lysine $(1 \mathrm{mM})$ were harvested during exponential phase at the same density.

RNA isolation and Northern blotting. Bacterial cultures $(25 \mathrm{ml})$ were harvested at a density of 70 Klett units (filter no. 54), which corresponds to mid-exponential phase when lysine is present in excess, by pouring onto $8 \mathrm{ml}$ frozen medium plus $0.25 \mathrm{ml} 1 \mathrm{M}$ sodium azide, followed by centrifugation at $12000 \mathrm{~g}$ for $10 \mathrm{~min}$ at $4{ }^{\circ} \mathrm{C}$. The cells were frozen at $-70^{\circ} \mathrm{C}$ and RNA was extracted by a modification of the methods of Wu et al. (1989) and Grandoni et al. (1992). This involved suspending the cells in $2 \mathrm{ml}$ of LETS buffer $(0.1 \mathrm{M} \mathrm{LiCl}, 10 \mathrm{mM}$ EDTA, $10 \mathrm{mM}$ Tris/ $\mathrm{HCl}, \mathrm{pH} 7 \cdot 4$ and $1 \%, \mathrm{w} / \mathrm{v}, \mathrm{SDS})$, adding $2 \mathrm{ml}$ phenol/ chloroform/isoamyl alcohol (25:24:1, by vol.) and $1 \mathrm{~g}$ acid- washed glass beads $(425-600 \mu \mathrm{m})$, and vortexing the mixture at $25^{\circ} \mathrm{C}$ for $4 \mathrm{~min}$, followed by heating at $75^{\circ} \mathrm{C}$ for $10 \mathrm{~min}$ with intermittent shaking. The aqueous layer was then collected and subjected to two additional phenol extractions. The final aqueous phase was supplemented with 0.1 vols $2 \mathrm{M} \mathrm{LiCl}$ and precipitated with 2 vols of ethanol. The resulting RNA precipitate was washed with $70 \%(\mathrm{v} / \mathrm{v})$ ethanol and redissolved in $0.1 \mathrm{ml}$ diethylpyrocarbonate-treated water. RNA electrophoresis was done on $1.25 \%(\mathrm{w} / \mathrm{v})$ agarose gels in $20 \mathrm{mM}$ MOPS, pH 6.5, $5 \mathrm{mM}$ sodium acetate, $1 \mathrm{mM}$ EDTA and $2 \%$ (v/v) formaldehyde, together with $0 \cdot 16-1.77 \mathrm{~kb}$ RNA size standards (Gibco/BRL). After electrophoresis at $90 \mathrm{~V}$ for $3.5 \mathrm{~h}$ the agarose gels were washed three times for 30 min each with diethylpyrocarbonate-treated water and the RNA was electrophoretically transferred to Hybond $\mathrm{N}$ membranes (Amersham) using a Genie electroblotting apparatus (Idea Scientific) in $20 \mathrm{mM}$ MOPS, pH 6.5, $5 \mathrm{mM}$ sodium acetate and $0.5 \mathrm{mM}$ EDTA for $2 \mathrm{~h}$ at $6 \mathrm{~V}$. The RNA blots were air-dried and crosslinked for $3 \mathrm{~min}$ in a Spectronics XL-1000 UV crosslinker.

Probes for Northern blots and hybridization conditions. An antisense RNA probe for the lys $C$ leader region was prepared by cloning the $0.42 \mathrm{~kb} \mathrm{Bg} / \mathrm{II}-M u n \mathrm{I}$ fragment of $l_{s} C$ DNA [nucleotides 261-689; nucleotides are numbered as in Chen et al. (1987)] into the BamHI and EcoRI sites of the pBluescript II pBC KS + polylinker region, followed by linearization by $\mathrm{XbaI}$ cleavage and transcription with bacteriophage T3 RNA polymerase, using $\left[\alpha^{32}\right.$ P]CTP as the labelled substrate. Antisense oligonucleotide probes, complementary to the regions indicated in Fig. 1, were prepared by labelling the $5^{\prime}$ ends of the following oligonucleotides using bacteriophage $\mathrm{T} 4$ polynucleotide kinase and $\left[\gamma^{32} \mathrm{P}\right] \mathrm{ATP}$ : probe $305-324,5^{\prime}$-CGCACCTCTATCTTCACCAT-3'; probe 360-379, 5'-CCTTTCAGCCTTTTTCACAG-3'; probe 471-490, 5'-TGAACAACGAGATAGCCCTC-3'; probe 550-569; 5'-AAGAGCGCTTTGTCCACAAT-3'; probe 597-616, 5'-CCCATGTATTACCACCCT'T'T-3'. The blots were prehybridized for $3 \mathrm{~h}$ at $43^{\circ} \mathrm{C}$ with $2 \times \mathrm{SSC}$ (SSC is $0.15 \mathrm{M} \mathrm{NaCl}, 0.015 \mathrm{M}$ sodium citrate), $1 \times$ Denhardt's reagent $(0.02 \%$ each of Ficoll, polyvinylpyrrolidone and BSA), and $1.5 \mathrm{mg}$ tRNA ml $\mathrm{m}^{-1}$, followed by hybridization in the same mixture supplemented with radioactive probe (about 500000 c.p.m.) for at least $15 \mathrm{~h}$ at $43^{\circ} \mathrm{C}$. The blots were washed repeatedly with $1 \times \mathrm{SSC}$ containing $0.1 \%$ SDS (three $15 \mathrm{~min}$ cycles at $25^{\circ} \mathrm{C}$ and two $15 \mathrm{~min}$ cycles at $33^{\circ} \mathrm{C}$ ) and then subjected to autoradiography using a storage phosphor screen and analysed on a Molecular Dynamics PhosphorImager SF with ImageQuant software (Molecular Dynamics).

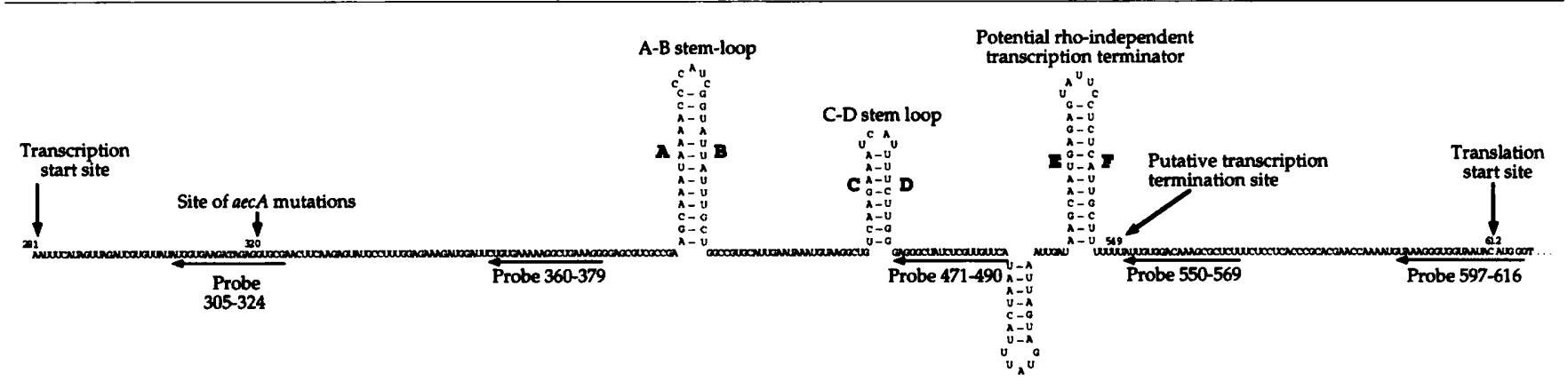

Fig. 1. Nucleotide sequence of the IysC leader region from B. subtilis, showing the postulated secondary structure of a putative transcription terminator element, the site of the aecA mutation in B. subtilis VB217, and the oligonucleotide probes used in this work. The transcription terminator structure is as proposed earlier (Chen et al., 1987) and can exist in equilibrium with an antiterminator structure in which stem B pairs with $C$, and $D$ with $E$. The coding region for the aspartokinase II $\alpha$ subunit starts at nucleotide 612 . Nucleotides are numbered as in Chen et al. (1987). 


\section{RESULTS}

\section{Effect of lysine and aecA mutations on lysC transcription}

The $\operatorname{lys}_{\mathrm{s}} \mathrm{C}$ operon can be derepressed either by starvation for lysine or by a class of cis-acting mutations known as $\operatorname{aec} A$. Earlier studies using translational and transcriptional lys $C^{\prime}:: l a c^{\prime} Z$ fusion strains suggested that both modes of derepression occurred at the level of transcription (Lu et al., 1991). To ascertain whether lysine indeed controlled $l y s C$ transcription, we directly examined the levels of lys $C$ mRNA under various conditions by the

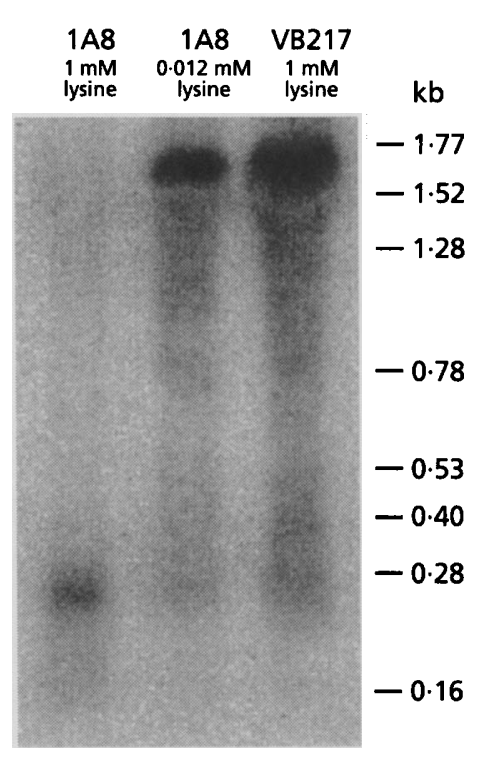

Fig. 2. Northern blot analysis of RNA extracted from $B$. subtilis strains $1 A 8$ and VB217, grown with limiting $(0.012 \mathrm{mM})$ or saturating $(1 \mathrm{mM})$ lysine. The blots were hybridized with a ${ }^{32} \mathrm{p}$ labelled antisense RNA probe complementary to nucleotides 261-689 of the lysC operon (Chen et al., 1987) as described in Methods. use of Northern blots. Cells of B. subtilis strain 1 A8 (lys-1) were grown either with limiting $(0.012 \mathrm{mM})$ or saturating (1 $\mathrm{mM}$ ) lysine, and RNA was extracted, subjected to Northern blotting and visualized by hybridization with a synthetic RNA probe which was complementary to 400 residues at the $5^{\prime}$ end of the lys $C$ transcript. Under conditions of lysine limitation, the major transcript was full-length lys $\mathrm{C}$ RNA $(1.6 \mathrm{~kb})$, whereas in saturating lysine, the full-length transcript almost completely disappeared and was replaced by a short $(0.27 \mathrm{~kb})$ lys $C$ specific RNA (Fig. 2). Interestingly, in B. subtilis strain VB217, which is genetically derepressed owing to an aec $A$ mutation, the full-length lys $C$ transcript was the major RNA species even under conditions of lysine excess and little $0.27 \mathrm{~kb}$ transcript was produced (Fig. 2).

\section{Mapping of the site of premature transcription termination with oligonucleotide probes}

To map the $0.27 \mathrm{~kb}$ lys $C$-specific transcripts within the lys $C$ operon, we hybridized Northern blots of RNA obtained from cells of $B$. subtilis $1 \mathrm{~A} 8$, harvested during either lysine starvation or growth with saturating lysine, with ${ }^{32}$ P-labelled oligonucleotides complementary to specific segments of the lys $C$ leader region as shown in Fig. 1. All oligonucleotide probes hybridized with the $1.6 \mathrm{~kb}$ full-length $l y s C$ transcript that was produced under conditions of lysine starvation, but only the probes upstream of nucleotide 490 and not those downstream of nucleotide 550 hybridized with the short transcript $(0.27 \mathrm{~kb})$ that was produced during growth with saturating lysine (Fig. 3). This is consistent with the notion that the $0.27 \mathrm{~kb}$ RNA molecules extend from the site of transcription initiation (nucleotide 281) through the rhoindependent terminator (nucleotide 550). Attempts to map the $3^{\prime}$ end of the $0.27 \mathrm{~kb}$ RNA more precisely by using oligonucleotide probes between nucleotides 490 and 550 were unsuccessful because these probes failed to hybridize even with full-length lys $C$ mRNA, perhaps because extensive secondary structure in the nucleotide

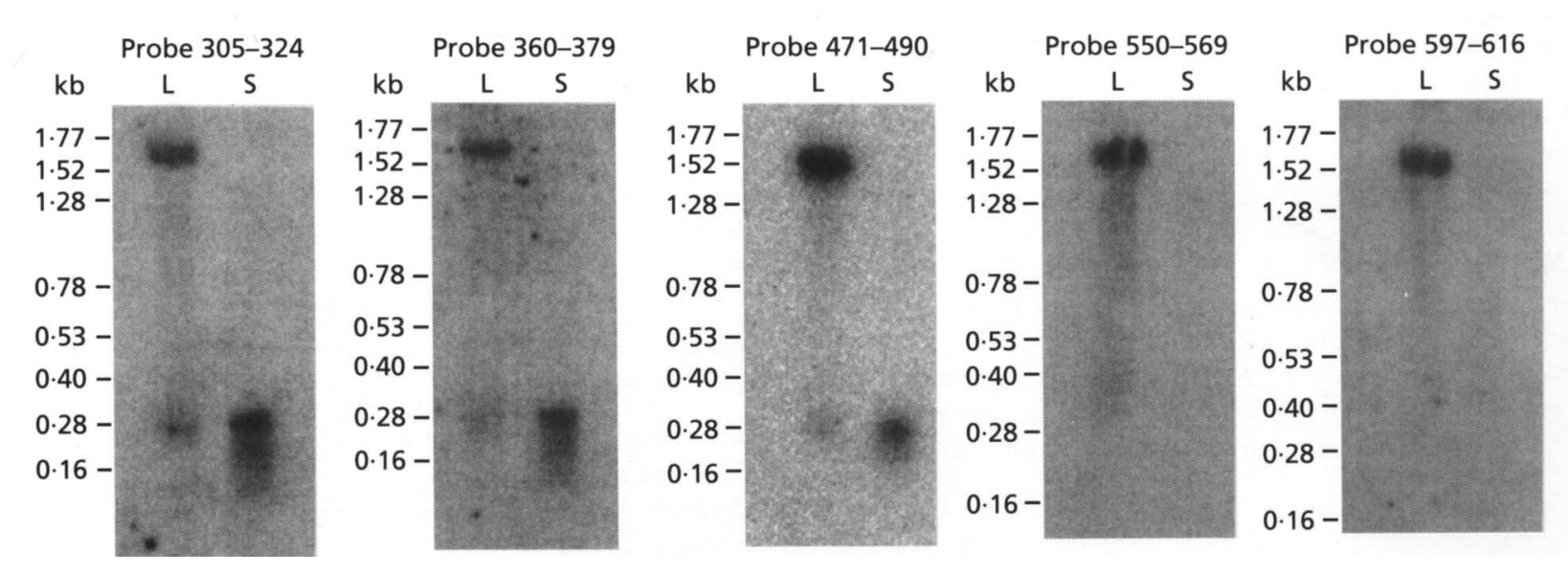

Fig. 3. Northern blot analysis of RNA extracted from B. subtilis strain 1 A8 grown with limiting (0.012 mM) (lanes L) or saturating $\left(1 \mathrm{mM}\right.$ ) (lanes S) lysine, using as probes ${ }^{32}$ P-labelled oligonucleotides complementary to the segments of the lys $C$ leader region indicated in Fig. 1 , as described in Methods. 
Table 1. Relative molar amounts of full-length and short lysC transcripts synthesized in the presence of limiting and saturating lysine

The relative amounts of radioactivity of the high and low molecular mass RNA components in the corresponding panels of Fig. 2 were estimated by integration using ImageQuant software. Image intensities are expressed as pixel values and no correction was made for background variation ( \pm 1000 pixels).

\begin{tabular}{|c|c|c|c|c|}
\hline \multirow[t]{2}{*}{ Transcripts } & \multicolumn{2}{|c|}{$\begin{array}{c}\text { Probe 305-324 } \\
\text { hybridization (pixels) }\end{array}$} & \multicolumn{2}{|c|}{$\begin{array}{c}\text { Probe 360-379 } \\
\text { hybridization (pixels) }\end{array}$} \\
\hline & $\begin{array}{c}0.012 \mathrm{mM} \\
\text { lysine }\end{array}$ & $\begin{array}{l}1 \mathrm{mM} \\
\text { lysine }\end{array}$ & $\begin{array}{c}0.012 \mathrm{mM} \\
\text { lysine }\end{array}$ & $\begin{array}{l}1 \mathrm{mM} \\
\text { lysine }\end{array}$ \\
\hline Full-length & 36200 & 1200 & 25700 & 0 \\
\hline Short & 16500 & 50900 & 8100 & 37800 \\
\hline Total & 52700 & 52100 & 33800 & 37800 \\
\hline
\end{tabular}

490-550 region of the mRNA molecules (see Fig. 1) prevented stable hybrid formation (data not shown).

The fact that the upstream oligonucleotide probes could hybridize in their entirety with both the full-length and the short lys $C$ transcripts (and therefore produced equivalent signals irrespective of the length of the RNA target) allowed comparison of the relative molar amounts of the various lysC RNA species synthesized by cells grown with excess or limiting lysine. As shown in Table 1 , lysine had no effect on the molar amounts of total lysC RNA synthesized but rather caused a quantitative shift of full-length $1.6 \mathrm{~kb}$ lys $\mathrm{C}$ mRNA to the truncated $0.27 \mathrm{~kb}$ RNA species.

\section{DISCUSSION}

Like most other operons that function in amino acid biosynthesis in bacteria, the $B$. subtilis lys $C$ operon, which encodes the first enzyme in the biosynthesis of lysine, is controlled by the intracellular concentration of its end product. When $B$. subtilis was starved for lysine, the predominant transcript of the $y_{s} \mathrm{C}$ operon was a $1.6 \mathrm{~kb}$ RNA species, which is the expected size for full-length lys $C$ mRNA (Chen et al., 1987). When lysine was present in excess, full-length lys $C \mathrm{mRNA}$ was almost completely replaced by a truncated $0.27 \mathrm{~kb}$ lys $C$ RNA species. Mapping of the $0.27 \mathrm{~kb}$ RNA by hybridization to oligonucleotides complementary to various regions of the lys $C$ leader region suggested that it corresponds to the $5^{\prime}$ terminal portion of lys $C \mathrm{mRNA}$, extending from the transcription start site (nucleotide 281) to the putative rho-independent transcription terminator (nucleotide 549).

Lysine had no effect on the total number of lys $C$-specific RNA molecules but caused a stoichiometric replacement of full-length mRNA by truncated RNA molecules. This suggested that lysine controls lys $C$ expression by promoting the premature termination of transcription rather than by inhibiting the initiation of transcription. (Another possible explanation, though not very likely, is that lysine promotes the decay of $l y s C \mathrm{mRNA}$, but that the high degree of RNA secondary structure arrests the progression of $3^{\prime}$-exonucleolytic degradation at the putative transcription terminator.) The observation that the lysineinduced accumulation of truncated transcripts was completely suppressed by an aec $A$ mutation involving a single G-to-A substitution in the leader transcript [nucleotide 320; Lu et al. (1991)] also supports the notion of a posttranscriptional control mechanism. Indeed, the fact that the lys $C$ operon transcript has an unusually long untranslated leader region with the potential for alternative secondary structures similar to the terminator/ antiterminator structures that play a role in the control of amino acid biosynthetic operons in Enterobacteriaceae (Kolter \& Yanofsky, 1982), had led to the earlier prediction that the lys $C$ operon of $B$. subtilis is controlled by a similar transcription attenuation mechanism (Chen $e t$ al., 1987). An important aspect of this prediction, that premature termination of transcription should occur at a rho-independent terminator that ends at nucleotide 549, is confirmed by the results presented in this paper.

On the other hand, the mechanism by which lysine promotes transcription attenuation is not yet clear. Originally, it was thought that control of premature transcription termination might be effected through the translation of a short open reading frame encoding a 24residue lysine-rich peptide, which overlaps the first stem-loop of the putative terminator structure (Chen et al., 1987). Such a mechanism is prevalent in the Enterobacteriaceae, where amino acid control of transcription is effected by the stalling of ribosomes at the cognate amino acid codons during translation of the leader peptide, thereby destabilizing the RNA secondary structure required for transcription termination (Kolter \& Yanofsky, 1982). However, experiments involving inframe translational fusions of the putative leader peptide with $\beta$-galactosidase provided no evidence for translation of this open reading frame under a variety of growth conditions (Yang $\mathrm{Lu} \& \mathrm{H}$. Paulus, unpublished results). Another observation that speaks against this type of terminator/antiterminator control mechanism is the complete suppression of premature transcription termination by a G-to-A substitution at nucleotide 320 , a position remote from both the open reading frame for the putative leader peptide (nucleotides 362-436) and the terminator stem-loop structures (nucleotides 393-544) (Fig. 1). Rather, our results suggest that the RNA segment around nucleotide 320, the site of many aec $A$ mutations (Lu et al., 1992), is an essential component of the transcription terminator.

The results on the $l_{s} C$ operon presented here bring the number of amino acid biosynthetic operons in B. subtilis that are known to be controlled by amino-acid-induced premature transcription termination to three, the others being the trp operon (Shimotsu et al., 1986) and the ilv-leu operon (Grandoni et al., 1992). [A fourth example may be cys $E$, which encodes the first enzyme for cysteine biosynthesis and is part of a complex operon also encoding 
the aminoacyl-tRNA synthases for glutamate and cysteine (Gagnon $e t$ al., 1994).] It is interesting that transcription attenuation in each of these three $B$. subtilis operons occurs by entirely different mechanisms, in contrast to the situation in E. coli, where attenuation control of many amino acid biosynthetic operons involves a single basic mechanism (Kolter \& Yanofsky, 1982). In the trp operon of $B$. subtilis, the transcription terminator in the leader transcript is stabilized by an RNA-binding protein that is active only when complexed with tryptophan (Babitzke \& Yanofsky, 1993; Gollnick, 1994); in the ilv-leu operon, an antiterminator structure seems to be specifically stabilized by uncharged tRNA ${ }^{\text {Leu }}$ but not by leucyltRNA $^{\text {Leu }}$ (Grandoni et al., 1993; Grundy \& Henkin, 1993); in the lys C operon, transcription attenuation seems to involve the lysine-dependent interaction between the site of the $\operatorname{aec} A$ mucation and a remote transcription terminator element by a mechanism yet to be defined. Clearly, the simple RNA secondary structure model for transcription attenuation in the $l y s C$ operon presented earlier (Chen et al., 1987), which was based on the E. coli paradigm, must be modified or extended to account for the role of nucleotide 320 in the structure of the terminator and the mechanism by which lysine modulates its function. Among the possibilities that need to be considered are more complex RNA structures than those shown in Fig. 1, especially ones involving tertiary structure elements such as pseudoknots as well as RNA-binding proteins whose activity may be modulated by lysine.

\section{ACKNOWLEDGEMENTS}

This work was supported by Grant R01 GM45879 from the National Institutes of Health.

\section{REFERENCES}

Anagnostopoulos, C. \& Spizizen, J. (1961). Requirements for transformation in Bacillus subtilis. J Bacteriol 81, 741-746.

Babitzke, P. \& Yanofsky, C. (1993). Reconstitution of Bacillus subtilis trp attenuation in vitro with TRAP, the $\operatorname{trp}$ RNA-binding attenuation protein. Proc Natl Acad Sci US A 90, 133-137.

Chen, N. Y., Hu, F. M. \& Paulus, H. (1987). Nucleotide sequence of the overlapping genes for the subunits of Bacillus subtilis aspartokinase II and their control region. $J$ Biol Chem 262, 8787-8798.

Dedonder, R. A., Lepesant, J. A., Lepesant-Kejzlarova, J., Billault, A., Steinmetz, M. \& Kunst, F. (1977). Construction of a kit of reference strains for rapid genetic mapping in Bacillus subtilis 168. Appl Environ Microbiol 33, 989-993.

Gagnon, Y., Breton, R., Putzer, H., Pelchat, M., GrunbergManago, M. \& Lapointe, J. (1994). Clustering and co-transcription of the Bacillus subtilis genes encoding the aminoacyl-tRNA synthetases specific for glutamate and for cysteine and the first enzyme for cysteine biosynthesis. J Biol Chem 269, 7473-7482.

Gollnick, P. (1994). Regulation of the Bacillus subtilis trp operon by an RNA binding protein. Mol Microbiol 11, 991-997.

Grandoni, J. A., Zahler, S. A. \& Calvo, J. M. (1992). Transcriptional regulation of the ilv-leu operon of Bacillus subtilis. J Bacteriol 174, 3212-3219.

Grandoni, J. A., Fulmer, S. B., Brizzio, V., Zahler, S. A. \& Calvo, J. M. (1993). Regions of the Bacillus subtilis ilv-leu operon involved in regulation by leucine. $J$ Bacteriol 175, 7581-7593.

Grundy, F. J. \& Henkin, T. M. (1993). tRNA as a positive regulator of transcription antitermination in B. subtilis. Cell 74, 475-482.

Kolter, R. \& Yanofsky, C. (1982). Attenuation in amino acid biosynthetic operons. Annu Rev Genet 16, 113-134.

Lu, Y., Chen, N. Y. \& Paulus, H. (1991). Identification of $\operatorname{aec} A$ mutations in Bacillus subtilis as nucleotide substitutions in the untranslated leader region of the aspartokinase II operon. $J$ Gen Microbiol 137, 1135-1143.

Lu, Y., Shevtchenko, T. N. \& Paulus, H. (1992). Fine-structure mapping of cis-acting control sites in the $l y s C$ operon of Bacillus subtilis. FEMS Microbiol Lett 92, 23-28.

Magnusson, K., Rutberg, B., Hederstedt, L. \& Rutberg, L. (1983). Characterization of a pleiotropic succinate dehydrogenase-negative mutant of Bacillus subtilis. J Gen Microbiol 129, 917-922.

Mattioli, R., Bazzicolupo, M., Federici, G., Gallori, E. \& Polsinelli, M. (1979). Characterization of mutants of Bacillus subtilis resistant to $S$-(2-aminoethyl)cysteine. J Gen Microbiol 114, 223-225.

Paulus, H. (1993). Biosynthesis of the aspartate family of amino acids. In Bacillus subtilis and Other Gram-positive Bacteria: Physiology, Biochemistry and Molecular Genetics, pp. 237-267. Edited by A. L. Sonenshein, J. A. Hoch \& R. Losick. Washington, DC: American Society for Microbiology.

Shimotsu, H., Kuroda, M. I., Yanofsky, C. \& Henner, D. J. (1986). Novel form of transcription attenuation regulates expression of the Bacillus subtilis tryptophan operon. J Bacteriol 166, 461-471.

Vold, B., Szulmajster, J. \& Carbone, A. (1975). Regulation of dihydrodipicolinate synthase and aspartate kinase in Bacillus subtilis. $J$ Bacteriol 121, 970-974.

Wu, J. J., Howard, M. G. \& Piggott, P. J. (1989). Regulation of transcription of the Bacillus subtilis spoII $A$ locus. $J$ Bacteriol 171, 692-698.

Yeh, E. C. \& Steinberg, W. (1978). The effect of gene position, gene dosage and a regulatory mutation on the temporal sequence of enzyme synthesis accompanying outgrowth of Bacillus subtilis spores. Mol \& Gen Genet 158, 287-296.

Received 20 November 1995; revised 12 February 1996; accepted 22 February 1996. 